limited $x$-irradiation could be given at intervals after transplantation, possibly combined with steroid therapy. Radiomimetic agents, such as 6-mercaptopurine, could be used instead of or as a supplement to $x$-irradiation. Dr. Merrill pointed out that the place of these potentially dangerous procedures was not yet clearly defined and he did not want to paint a rosy picture.

In looking to the future of renal transplantation, Dr. Merrill emphasized that, immunologically, the kidney was a relatively favoured organ. It did not produce a graftversus-host reaction. Furthermore, renal transplantation was equivalent to giving a large dose of antigen intravenously - a method known to facilitate the establishment of tolerance experimentally. Possible developments lay in new techniques of " matching " tissues, selective injury to lymphopoietic tissue without destruction of bone marrow, and use of anti-serotonin agents to prevent vascular rejection mechanisms.

\section{Discussion on Renal Transplantation}

After his lecture Dr. J. P. Merrill was the moderator of a panel discussion on renal transplantation, in which the members of the panel were Dr. J. R. Anderson (Glasgow), Professor R. McWhirter (Edinburgh), Professor M. F. A. Woodruff (Edinburgh), and Dr. J. S. Robson (Edinburgh).

Dr. ANDERSon referred to the basic problems in immunology fundamental to renal transplantation. The immune response could be suppressed by modifying $(a)$ the graft, or $(b)$ the host. In the case of the kidney, the closer the donor and recipient were genetically, the weaker would be the immune response. In closely related pairs the number of antigens capable of producing immune response was very small, and in similar twins, antigenically alike, the immune response was absent. The graft, therefore, took successfully.

Methods of producing tolerance were (1) conditioning the foetus, too immature to show immune response, by a graft (a suspension of cells). When the foetus grew to maturity it would have developed specific tolerance to the donor of the original graft, and could accept further grafts successfully. (2) In the adult the immune reaction could be suppressed by irradiation, as had been shown by Merrill and his colleagues, and also by Küss in Paris. When whole-body irradiation had been given it was possible that the graft itself might then react against the host. Dr. Anderson concluded by referring to the possibility that the foetus and the mother might develop mutual partial tolerance during gestation.

Dr. MerRILl said that renal transplants between parents and children had been disappointing, but the possibility that infants with icterus neonatorum, who had received large transfusions, might develop tolerance to a specific blood donor should be explored. He referred to a renal homograft which had already survived for more than 18 months in a case of non-identical twins. Tolerance was produced by repeated small doses of whole-body irradiation, and he considered that this technique could perhaps be combined with the use of 6-mercaptopurine.

Professor WoODRUFF said that, in his experience, compatibility of blood groups was not a sufficient guarantee of success in homotransplantation. The homograft problem had been solved in the laboratory, where a high degree of tolerance to homotransplants could be induced in a mammal by the post-natal injection of donor cells. Nature occasionally produced this result in nonidentical (dizygotic) twins who, on account of admixture of their placental circulations, became erythrocyte chimeras. Such twin chimeras were tolerant of each other's tissues and could interchange skin grafts.

Professor McWhiRTER, referring to whole-body irradiation, said that a sublethal dose given to a patient to condition him to receive a graft was difficult to estimate. Under $400 \mathrm{r}$ was perhaps the safest, and with supervoltage radiation the dose could be reduced. The risk of leukaemia, which was real and was also present with radiomimetic agents, was well justified.
Dr. RoBson then spoke of the problem of infection in cases of renal transplantation. He firmly believed that infection in the recipient should be treated when it arose, and not before. The policy of "no prophylactic antibiotics" should be emphatically imposed. Dr. MERRILL agreed with that, but prophylactic antibiotics should be given when infection existed in the recipient.

Professor WoodrufF considered that the graft-recipient reaction could be limited by broad-spectrum antibiotics, and Dr. MERRILL agreed that some of the effects of " secondary disease" could be due to infection. Professor WooDrufr also stressed the point that micro-methods of blood analysis to minimize the quantity of blood taken from the patient were desirable. Dr. MerRILl said that such methods were being developed successfully.

\section{New Appliances}

\section{A SIMPLE CRUTCH}

Mr. DenIS BURKITT, specialist surgeon, Uganda Medical Services, writes: In underdeveloped countries many people are deprived of effective medical treatment owing to limited hospital accommodation. Yet patients with leg injuries are often retained longer than necessary for lack of a suitable crutch to render them ambulant.

Hospital authorities are naturally reluctant to issue elaborate adjustable crutches which might not be recovered, and the commonly used " $\mathrm{T}$ " model is useless for weightbearing. Moreover, there are many sedentary cripples who, with a means of locomotion, might be converted into ambulant workers.

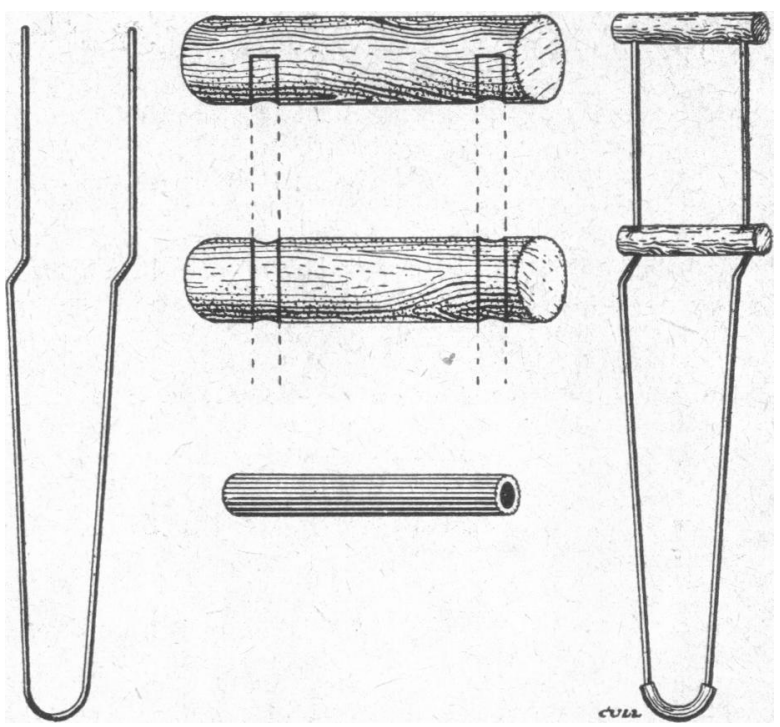

A search has been made for a crutch pattern combining effectiveness and comfort with simplicity and economy. The pattern illustrated appears to meet these requirements. The only materials required are: (1) iron rods as used by any building contractor $\left(\frac{3}{8}\right.$ in. $\left(1 \mathrm{~cm}\right.$.) diameter for adults, $\frac{1}{4}$ in. (0.6 cm.) diameter for children); (2) a broom handle; and (3) rubber tubing (that used for garden hose is very satisfactory); its life can be considerably lengthened by using a large piece of tubing which can be moved along the iron rod as the weight-bearing area becomes worn. The handgrip is placed at one-third of the length of the crutch from the upper end.

A crutch can be shortened by cutting a piece from the ends of the iron rods, and the hand-grip can be raised by threading a short length of piping on to each limb before placing the hand-grip. The rubber tube, when worn, can 
be easily replaced after removing the two cross-bars. The " $U$ " bottom is thought to be better than the conventional peg end.

Such a crutch can be made at any hospital in a matter of minutes with a minimum of equipment. This pattern has been adopted by the Uganda Medical Service and the Mulago Round Table Polio Clinic. The diagram was drawn by Mr. Peter Gull.

\section{A SET OF GUIDE AND BOUGIES TO FACILITATE INSERTION OF MOUSSEAU- BARBIN TUBES}

Mr. F. T. Crossling, senior registrar, Stobhill General Hospital, Glasgow, writes: It is an unfortunate fact that many cases of carcinoma of the oesophagus, particularly where the mid or upper third is involved, are beyond surgical cure when the patient is first seen. ${ }^{12}$ When one is confronted with this situation on clinical investigation or at operation, it is still essential to attempt some form of palliation to enable the patient to swallow, and intubation of some kind is often the best method. ${ }^{3}$ s

The original Souttar tube has the disadvantage that food becomes enmeshed in its wall and causes blockage. Also it may readily be displaced and passed beyond the stricture into the stomach. However, there are now a number of modified forms made of plastic materials." s s From considerable experience in the use of the Mousseau-Barbin tube we find that food is less likely to adhere to a plastic tube, and that the large flange prevents displacement. The Mousseau-Barbin type has been justifiably popular despite possible trouble with pressure necrosis at the funnel end of the tube, but in our hands preliminary dilatation with bougies has been a greater problem. ${ }^{\top}$ One can only too easily transgress the oedematous and infiltrated oesophageal wall even when great care is taken, although it is a remarkable fact that, despite the presence of a traumatic rupture of the oesophagus due to bougienage, a successfully passed Mousseau-Barbin tube will seal the gap and continue to function satisfactorily without the development of mediastinitis.

The eventual passage of one bougie as confirmed by a finger in the stomach is no guarantee that subsequent larger bougies will follow the same route. Therefore, in order to facilitate both bougienage and insertion of the tube, a set of gum-elastic oesophageal bougies has been devised which can be linked together by a simple screw attachment to form a continuous length. The set, which consists of five bougies, sizes 13, 15, 17, 19, and 21 (English gauge) (Fig. 1), gives

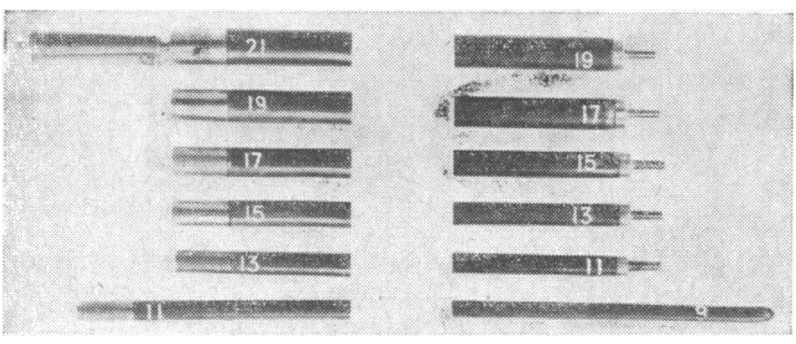

FIG. 1

sufficient dilatation to permit easy insertion of a size 10 or 12 Mousseau-Barbin tube. The guide bougie, which is of gauge 11 , is $70 \mathrm{~cm}$. long $(15 \mathrm{~cm}$. longer than the standard gum-elastic bougie) (Fig. 2). It can thus be passed right into the stomach while leaving sufficient length projecting from the mouth to facilitate attachment of subsequent bougies. As the guide bougie is pulled out of the gastrotomy one bougie after another is attached and pulled through until enough dilatation is achieved. The cone-shaped adapter, which can be screwed into the proximal end of any of the bougies, is then attached, and to this the tip of the
Mousseau-Barbin tube is secured by suture and is pulled through (see Fig. 2). The conical shape of the adapte allows the fixation suture to be recessed behind the last bougie and so prevents further trauma to the friable oesophageal wall.

A Mousseau-Barbin "stylet" is available, and this certainly facilitates introduction but does not allow of any

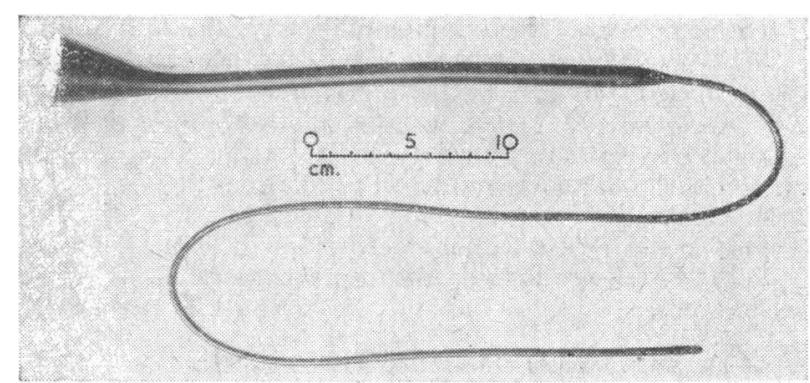

FIG. 2

gradual dilatation of the malignant stricture. We feel that the method described is safer. It has now been successfully employed in a number of cases in Stobhill Hospital, Glasgow.

I am grateful to Mr. J. Hutchison for permission to publish this report.

The equipment was manufactured by Charles F. Thackray Ltd., and I am indebted to their representative. Mr. Bury. for his close co-operation.

REFERENCES

1 Collis, J. L., Lancet, 1957, 2, 613

Mullard, K.' S., ibid. 1960, 1, 677

Moghissi, K., ibid., 1960, 1, 679.

Bickford, B. J., ibid., 1960, 1, 1077.

Mousseau, Le Forestier, J., Barbin, J., and Hardy, Arch. Mal. Appar. dig., 1956, 45, 208.

- Celestin, L. R., Ann. roy. Coll. Surg. Engl., 1959, 25, 165.

Jamieson, R. Ä., Cameron, E., and Clark, R. G., Lancet, 1960 1,923 .

\section{Nova et Vetera}

\section{MEMOIRS OF F.R.S.'s}

With commendable promptitude a sixth volume in this informative series has appeared. ${ }^{1}$ It contains memoirs with full bibliographies of 17 Fellows who died from 1958 to 1960 . They comprise two botanists; three zoologists (including two entomologists); five chemists ; five physicists (including one metallurgist) ; one pharmacologist; and a millionaire philanthropist. Seven of these were foreigners - two Frenchmen, two Germans, one Austrian, one Dane, and one American. The memoirs are written with personal knowledge of the deceased Fellows; and for the most part by those who have worked with them.

Place aux dames, and the volume opens with an account of Mrs. Agnes Arber, the botanist, an authority on the anatomy and morphology of monocotyledonous plants. In her later years she wrote on philosophy. She was the third woman to be elected F.R.S. Much of the research work of Fellows recorded here was in different branches of pure and applied science, but some of it has a direct bearing on medicine-for example, the investigations of the German physicist Max von Laue on $x$-ray diffraction in which he succeeded where

'Biographical Memoirs of Fellows of the Royal Society. Volume 6. (Pp. 295; illustrated. 30s.) London: The Royal Society, Burlington House, W.1. 1960. 